\title{
O Que Sigmund Freud Nos Fala Sobre O Ódio?
}

\author{
Joelma Galvão De Lemos1
}

\section{Resumo}

O ódio e o amor aparecem na obra de Sigmund Freud (1856-1939) muitas vezes de maneira simultânea e ambivalente; ao falar de um, comenta-se ainda que brevemente do outro. Apesar de o teórico não ter definido o ódio como um conceito, esse afeto aparece em vários momentos da elaboração de sua teoria, desde os textos clínicos aos textos sociais, demonstrando sua importância no processo de formação do sujeito, das relações de identificação que este estabelece ao longo da vida e, consequentemente, dos vínculos afetivos que circulam pela sociedade. A leitura dos textos freudianos nos ajuda a compreender melhor porque é tão fácil ao homem fazer uso do discurso de ódio e até mesmo de ações agressivas e violentas no convívio com o outro.

Palavras-Chave: Ódio; Psicanálise; Identificação.

1 Psicóloga, psicanalista, com mestrado em Psicologia Social pelo Programa de Pós-Graduação de Psicologia na Universidade Federal de Sergipe e doutoranda neste programa. E-mail: joelmalemos@outlook.com; telefone: (79) 99103-1525. 


\section{INTRODUÇÃO}

Falar do ódio a partir dos textos de Sigmund Freud é falar também do amor, uma vez que ocorrem de maneira simultânea na vida do sujeito, desde seu processo de constituição psíquica à sua relação social ao longo da vida. Este tema será apresentado a partir de uma ordem cronológica, acompanhando o desenvolvimento da obra de Freud. Escolhi essa opção a fim de demonstrar o quanto o ódio está presente no processo de desenvolvimento do sujeito, bem como da sociedade. A leitura desses textos demonstra, ainda, que Freud não desassociava o sujeito do social, mas apenas apresentava artigos didaticamente elaborados, alguns mais clínicos e outros, sociais. O autor chegou a afirmar que muitas vezes é mais fácil estudar o sujeito a partir das relações sociais do grupo ao qual pertence (FREUD, [1930] 1996).

O ódio aparece em "A interpretação dos sonhos" ([1900,1901] 1996), quando Sigmund Freud cita a análise que fizera do sonho que tivera com Irma e seus amigos Otto e Leopoldo2. Ele explica que o "conteúdo deste [sonho] foi a realização de um desejo, e seu motivo foi um desejo" (FREUD, [1900] 1996, p. 153), pois percebera que no sonho estava se vingando de Otto, por este se apressar demais na conclusão de seus tratamentos, assim como por ter lhe dado um licor não muito bom, e também de sua paciente por não o ter obedecido (FREUD, [1900] 1996). Em seguida, ao se ater a sua resistência em analisar o sonho, conseguiu compreender que a "a afeição, no sonho, não dizia respeito ao conteúdo latente, aos pensamentos que estavam por trás do sonho; estava em contradição com eles e tinha o propósito de ocultar a verdadeira interpretação do sonho". Freud lembrara do "quanto havia odiado, e de como declarara que o sonho era puro absurdo" (FREUD, [1900] 1996, p.175). Ele percebeu que sua resistência em analisar o sonho decorria de perceber a contradição de seus sentimentos para com sua paciente e seu amigo, mais especificamente em se dar conta de que por traz de seus sentimentos de afeição por ambos havia também ódio por eles.

Ainda sobre o ódio, Freud comenta sobre os adultos que mantêm uma relação afetuosa com seus irmãos e irmãs, mas que em sua infância tiveram inúmeras inimizades entre si. "O filho mais velho maltrata o mais novo, fala mal dele e rouba- 
Ihe os brinquedos, ao passo que o mais novo se consome num ódio impotente contra o mais velho, a quem inveja e teme [...]" (FREUD, [1900] 1996, p. 277). Para o autor, "muitas pessoas, portanto, que amam seus irmãos e irmãs e se sentiriam desoladas se eles morressem, abrigam desejos maléficos contra eles em seu inconsciente, datando de épocas anteriores; e estes são passíveis de se realizarem nos sonhos" (FREUD, [1900] 1996, p. 278). De acordo com Sigmund, o ódio aparece facilmente nas relações sociais, e para percebermos basta imaginarmos uma pessoa com a qual nos relacionamos, mas que também odiamos, e que apesar de não admitirmos, pois somos impedidos pela nossa moralidade, temos um desejo de que ela seja infeliz. Caso algo de mal lhe aconteça, suprimimos essa satisfação diante do ocorrido e nos impomos "pensamentos de pesar [...] mas sucede então que a pessoa odiada, por alguma transgressão sua, envolve-se num merecido dissabor, quando isso acontece, posso dar rédea solta à minha satisfação por ela ter recebido uma punição justa" (FREUD, [1901] 1996, p. 510-511). A satisfação é acrescida do ódio que sentimos por essa pessoa, que até então não se manifestara, pois estava impedida pelo afeto, mas que por conta da mudança da circunstância já não é mais necessário impedi-la (FREUD, [1901] 1996).

Em "Três ensaios sobre a teoria da sexualidade" (1905), o autor, ao comentar sobre as fontes da sexualidade infantil, afirma: "[...] descobrimos até agora que a excitação sexual nasce (a) como a reprodução de uma satisfação vivenciada em relação a outros processos orgânicos [...] como expressão de algumas 'pulsões' [...] como a pulsão de ver e a pulsão para a crueldade" (FREUD, [1905] 1996, p. 188). Nessa fase, a atividade sexual ainda não está separada da nutrição e o infans ainda não separa o que é interior e exterior, e é possível perceber sua agressividade quando não consegue a satisfação de suas necessidades. Freud explanará com mais clareza sobre essa questão em Os instintos e suas vicissitudes ([1915] 1996), texto que veremos mais à frente.

Em "Totem e tabu" (1913), mostra como inicialmente os filhos desamparados, sozinhos, expulsos do clã pelo pai, se unem a partir do ódio a este, se organizam e o assassinam. O ódio pelo pai é o fio de ligação entre os filhos e o que os impulsiona a realizar seu desejo. Contudo, após a realização do parricídio, a prole experimenta o sentimento de culpa, pois assim como sentia ódio pelo pai, percebem também que o amava. O ódio e o amor muitas vezes ocorrem de maneira ambivalente na vida do 
sujeito. Os filhos, numa tentativa de identificação com o pai que assassinaram, o devoram, ingerindo suas partes - e ilusoriamente, seu poder. Esses também se dão conta de que é preciso algo que barre seus próprios filhos e irmãos, para que não Ihes aconteça o mesmo que ocorrera com seu pai. É nessa tentativa de autopreservação que é instaurada a interdição do incesto, já que nenhum homem pode ficar com as mulheres do seu clã, todos terão que procurar uma mulher em outro clã (FREUD, [1913] 1996). É por via da criação e implantação dessa interdição que se impede que o ódio seja usado como instigador de violência para com os seus, uma vez que não brigarão entre si pelas mulheres do seu grupo, e também como sentimento de ligação e união entre o clã, pois terá que se unir para conseguir parceiras em outros clãs.

Em "Totem e tabu" (1913), o ódio é apresentado a partir da relação entre os irmãos, os filhos e o pai da horda primeva, como sentimento de ligação e união, mas também como sentimento usado para a autopreservação. Em "Sobre o narcisismo: uma introdução" (1914) e "As pulsões e suas vicissitudes" (1915), Freud comenta sobre a relação amor e ódio na constituição do ego. O humano ao nascer é um ser pulsional que não diferencia o que é externo do que é interno, tendo inicialmente dois objetos sexuais, ele próprio e sua mãe - ou a pessoa que o alimenta, cuida e o protege (FREUD, 1914). Suas "primeiras satisfações sexuais auto eróticas [sic] são experimentadas em relação com funções vitais que servem à finalidade de autopreservação. As pulsões sexuais estão, de início, ligadas à satisfação das pulsões do ego; somente depois é que elas se tornam independentes destes" (FREUD, [1914] 1996, p. 94).

O ódio [...] provém do repúdio primordial do ego narcisista ao mundo externo com seu extravasamento de estímulo. Enquanto expressão da reação do desprazer evocado por objetos, sempre permanece numa relação íntima com os instintos auto preservativo [sic], de modo que os instintos sexuais e os do ego possam prontamente desenvolver uma antítese que repete a do amor e do ódio. Quando os instintos do ego dominam a função sexual, com é o caso na fase da organização anal-sádica, eles transmitem as qualidades de ódio também à finalidade instintual (FREUD, [1915] 1996, p. 143-144).

O ego tenta, por meio do amor, obter uma satisfação erótica a partir dos seus impulsos pulsionais e pela obtenção de prazer do órgão, assim como também busca incorporar objetos externos que oferecem prazer, o que demonstra seu narcisismo. Contudo, quando não consegue incorporar o objeto, o ego o repudia por meio do ódio. O ego tenta, a partir do amor, manter o que lhe causa prazer; e a partir do ódio, o que Ihe causa desprazer (FREUD, [1915] 1996). O ódio, nesse caso, está a serviço de 
Eros, uma vez que é usado a fim de preservar o ego. Por isso Freud afirma que somente depois de "estabelecida a organização genital é que o amor se torna o oposto do ódio" (FREUD, [1915] 1996, p. 143).

Em "Luto e melancolia" ([1917a (1915)] 1996), o criador da psicanálise fala da hostilidade do ego para consigo no estado melancólico. De acordo com essa perspectiva, o luto é a "reação à perda de um ente querido, à perda de alguma abstração que ocupou o lugar de um ente querido, como país, a liberdade ou o ideal de alguém, e assim por diante" (FREUD, [1917a (1915)] 1996, p. 249). Apesar do afastamento do indivíduo em relação à vida nesse período, ele não é em hipótese alguma considerado como tendo uma patologia; e nesse caso não se submete a pessoa que está vivenciando o luto a um tratamento, pois essa precisa apenas de um tempo para lidar com sua nova realidade, com a falta e com o desinvestimento naquele que perdera (FREUD, [1917a (1915)] 1996). Já a melancolia é um estado em que o indivíduo traz consigo um

desânimo profundamente penoso, acompanhado da cessação de interesse
pelo mundo externo, a perda da capacidade de amar, a inibição de toda e
qualquer atividade e, uma diminuição dos sentimentos de autoestima [sic] a
ponto de encontrar expressão em auto recriminação [sic] e auto
envilhecimento culminando numa expectativa delirante de punição (FREUD,
[1917a (1915)] 1996, p. 250).

Isso ocorre porque em algum momento o indivíduo se decepcionou ou se frustrou com a pessoa a qual estava ligado libidinalmente e por conta disso rompeu com a relação. No estado normal, esse investimento libidinal é direcionado a outro objeto, mas no caso da melancolia, a libido livre não se deslocou para outro objeto e, sim, para o ego. Nesse caso, o ego estabeleceu uma identificação com o objeto abandonado e sua perda "se transformou numa perda do ego e o conflito entre ego e a pessoa amada, numa separação entre a atividade crítica do ego e o ego enquanto alterado pela identificação" (FREUD, [1917a (1915)] 1996, p. 255). Para o ego não se trata apenas da perda de um objeto, mas, sim, da perda de si mesmo.

Apesar de a melancolia se parecer com o luto, nesta o mundo parece ser "pobre e vazio" e "a inibição e a perda de interesse são explicadas pelo trabalho de luto no qual o ego é absorvido" (FREUD, [1917a (1915)] 1996, p. 251); já na melancolia é o ego que é apresentado pelo paciente como pobre e vazio, "incapaz de qualquer realização e moralmente desprezível; ele se repreende e se envilece, esperando ser expulso e punido" (FREUD, [1917a (1915)] 1996, p. 252). 
A melancolia é "uma reação à perda real de um objeto amado" acompanhada pela ambivalência dos sentimentos de ódio e amor, que muitas vezes ocorre "nas relações amorosas" (FREUD, [1917a (1915)] 1996, p. 256). O objeto amado pode ser renunciado, mas o amor por ele, não; pois esse amor se refugia na identificação narcisista, daí a ambivalência de amor e ódio. Muitas vezes,

\begin{abstract}
os pacientes conseguem, pelo caminho indireto da autopunição [sic], vingarse do objeto original e torturar o ente amado através de sua doença, à qual recorrem a fim de evitar a necessidade de expressar abertamente sua hostilidade para com ele. Afinal de contas, a pessoa que ocasionou a desordem emocional do paciente, e na qual a doença se centraliza, em geral se encontra em seu ambiente imediato. A catexia erótica do melancólico no tocante a seu objeto sofreu assim uma dupla vicissitude: parte dela retrocedeu à identificação, mas outra parte, sob influência do conflito devido à 'ambivalência', foi levada de volta à etapa de sadismo que se acha mais próximo do conflito (FREUD, [1917a (1915)] 1996, p. 257).
\end{abstract}

Na melancolia, "o ódio e o amor se digladiam; um procura separar a libido do objeto, o outro, defender essa posição da libido contra o assédio" (FREUD, [1917a (1915)] 1996, p. 261), e o ego sofre as consequências dessa luta entre as pulsões, daí o desenvolvimento de uma doença psíquica, em que satisfaz ambas as pulsões, mas também como a tentativa de diminuir seu sofrimento.

Em "Reflexões para os tempos de guerra e morte" (1917), Freud inicia seu texto falando sobre a desilusão da guerra ao afirmar que "as nações civilizadas se conhecem e se compreendem tão pouco, que uma podem voltar-se contra a outra com ódio e asco" (FREUD, [1917b] 1996, p. 288). Demonstra o quão cruéis e sanguinários os homens podem ser em períodos de guerra, deixando ao seu fim uma destruição e um estrago para além do território, um rompimento nas relações sociais entre os lados opostos muitas vezes quase que intransponível. O autor comenta como o Estado "proíbe ao indivíduo a prática do mal, não porque deseja aboli-la, mas porque deseja monopolizá-la, tal como o sal e o fumo" (FREUD, [1917b] 1996, p. 290), e usála quando Ihe convém, como nas guerras contra outros Estados. Ainda nesse texto, declara que "a natureza humana consiste em impulsos instintuais de natureza elementar, semelhantes em todos os homens e que visam à satisfação de certas necessidades primevas. Em si mesmos estes não são nem bons e nem maus" (FREUD, [1917b] 1996, p. 290). Sua expressão ocorre de acordo com "as necessidades e exigências da comunidade humana” (FREUD, [1917b] 1996, p. 290). Amor e ódio são encontrados na mesma pessoa, e somente quando as vicissitudes instintuais são superadas é que se formam o que é chamado de caráter (FREUD, 
[1917b] 1996). A transformação das pulsões ditas más em boas é ocasionada por fatores internos e externos, uma vez que o ego tenta se preservar e satisfazer sua necessidade de amor. Inicialmente, o sujeito deseja o amor de sua mãe, seu pai e, conforme se desenvolve, deseja também o amor dos membros do grupo social ao qual pertence. Contudo, conforme o pequeno infans cresce, ele começa a percebe que para ter o amor da mãe e demais pessoas do seu círculo social terá que fazer o que demandam dele. Isso significa que, para conseguir o objeto amado, o sujeito precisa abrir mão de sua satisfação pulsional imediata em troca de uma satisfação paliativa.

Em "Além do princípio de prazer" (1920), Sigmund Freud apresenta uma nova dualidade das pulsões: se antes as pulsões de sexualidade eram ligadas a Eros, e as pulsões de autoconservação, ao ódio, o autor afirma que as pulsões sexuais e as de autopreservação são representantes de Eros, enquanto o ódio representa a pulsão de morte. Freud percebeu em suas observações que essas pulsões sempre ocorrem de maneira ambivalente e que estão constantemente lutando, desde o início da vida. Um dos exemplos dessa ambivalência ocorre entre sujeitos pertencentes a um mesmo grupo. Vejamos o exemplo das religiões, apresentado por Freud em "Psicologia de grupo e a análise do ego" (1921), em que os irmãos fiéis se ligam uns aos outros pelo amor entre eles e pelo ódio que é direcionado àqueles que não pertencem à sua fé. Daí entendermos por que muitos religiosos não aceitam e, inclusive, atacam outras instituições religiosas. Ainda de acordo com o autor, os membros de um coletivo podem se identificar ao seguirem o mesmo líder ou por compartilharem um ideal. Assim, muitos tentam imitar o líder, pois se identificam com ele e geralmente fazem prontamente o que Ihes solicita. $O$ vínculo afetivo dos membros se fortalece, pois amam os seus iguais, se submetem ao mesmo líder que admiram, ou à mesma causa, e direcionam o ódio àqueles que não pertencem ao seu coletivo ou não compartilham do seu ideal. Assim, mantêm-se unidos pela pulsão de vida, por meio da identificação entre si e com o líder, e do ódio ao outro, a partir de discursos de ódio, atos violentos e agressivos contra os que não pertencem ao seu grupo.

A identificação é ainda comentada em "O Ego e o Id" (1923), obra em que o autor descreve o processo de desenvolvimento do ego, do superego e do id. Se inicialmente o prematuro ser humano não consegue distinguir o que é externo e interno, com o passar do tempo ele, que era um emaranhado de pulsões, passa a 
distinguir o que é externo e interno. Por meio da pulsão de autopreservação consegue investir libidinalmente em si; e a partir da pulsão sexual, no objeto externo inicialmente, sua mãe ou alguém que desempenha essa função. O pequeno infans que está se desenvolvendo precisa de cuidados e alimentos, mas também de carinho e afeto dos que cuidam dele. Nessa fase admira seus cuidadores e tenta agradá-los se submetendo a eles, a fim de não perder o seu amor. No entanto, no caso do menino que admira o pai e que tem sua mãe como objeto sexual, pois deseja tê-la para si, percebe que ela não está à sua disposição e que seu pai o impede de realizar seu desejo. O infans, ao mesmo tempo em que ama o pai, experimenta um sentimento ambivalente, pois o ama e o admira, mas também o odeia, pois ele o impede de realizar seu desejo.

Freud vai demonstrando no desenvolver da teoria psicanalítica que o processo de constituição do sujeito é marcado pela ambivalência entre as pulsões de vida e morte, pela renúncia a satisfações libidinais e pela obtenção de prazer por meio de satisfações substitutivas. No entanto, abrir mão de seu prazer a fim de conseguir viver em sociedade não é algo fácil aos homens, pois estes

\begin{abstract}
São criaturas entre cujos dotes instintivos deve-se levar em conta uma poderosa cota de agressividade. Em resultado disso seu próximo é, para eles, não apenas um ajudante potencial ou um objeto sexual, mas também alguém que os tenta a satisfazer sobre ele a sua agressividade, a explorar sua capacidade de trabalho sem compensação, utilizá-lo sexualmente sem o seu consentimento, apoderar-se de suas posses, humilhá-lo, causar-lhe sofrimento, torturá-lo e matá-lo (FREUD, [1930 (1929)] 1996, p. 116).
\end{abstract}

Essa inclinação da humanidade à agressão, ao domínio do outro, faz com que o homem utilize esforços supremos a fim de inibi-los ou mantê-los sob controle. Para se viver em sociedade, o homem impôs barreiras a satisfações sexuais e agressivas, "trocou uma parcela de suas possibilidades de felicidade por uma parcela de segurança" (FREUD, [1930 (1929)] 1996, p. 119).

Para Freud ([1930 (1929)] 1996, p. 126), "a civilização constitui um processo a serviço de Eros, cujo propósito é combinar indivíduos humanos isolados, depois famílias e, depois ainda, raças, povos e nações numa única grande unidade, a unidade da humanidade". Sigmund descobriu, ainda, que o ódio, representante da pulsão de morte, está "lado a lado de Eros e que com este divide o domínio do mundo. [...] Eros e a Morte, entre o instinto de vida e o instinto de destruição, tal como ela se elabora na espécie humana" (FREUD, [1930 (1929)] 1996, p. 126). Ou seja, a vida é 
a luta entre essas pulsões e "a evolução da civilização pode ser simplesmente descrita como a luta da espécie humana pela vida" (FREUD, [1930 (1929)] 1996, p. 126).

Em "Por que há guerra?" (1933-1932), Freud, em resposta a Albert Einstein, explica, como já vimos em alguns dos seus textos, que o homem traz em si um desejo de agressão e destruição e que basta olharmos para a história da humanidade para nos depararmos com incontáveis atos de crueldade e violência realizados por ele. Explica ainda que:

A satisfação desses impulsos destrutivos naturalmente é facilitada por sua
mistura com outros motivos de natureza erótica e idealista. Esse instinto está
em atividade em toda criatura viva e procura levá-la ao aniquilamento, reduzir
a vida à condição original de matéria inanimada. Portanto, merece, com toda
seriedade, ser denominado instinto de morte, ao passo que os instintos
eróticos representam o esforço de viver. O instinto de morte torna-se instinto
destrutivo quando, com o auxílio de órgãos especiais, é dirigido para fora,
destruindo uma vida alheia. Uma parte do instinto de morte, contudo, continua
atuante dentro do organismo, e temos procurado atribuir numerosos
fenômenos normais e patológicos a essa internalização do instinto de
destruição (FREUD, [1933 (1932)] 1996, p. 203-204).

A vida como a conhecemos ocorre exatamente por conta dessa relação intrínseca entre pulsão de morte e vida, por isso não é possível eliminar os impulsos agressivos; porém, segundo o teórico, é possível "desviá-los num grau tal que não necessitem encontrar expressão na guerra" (FREUD, [1933 (1932)] 1996, p. 204). Para isso, Freud sugere que se contraponha Eros à pulsão de morte por meio do incentivo às relações afetivas, ou seja, do amor sem a finalidade sexual e a ligação a partir da identificação com aqueles que defendem outros meios de resolução dos problemas coletivos, abrindo mão da agressividade como meio de resolver os conflitos sociais (FREUD, [1933 (1932)] 1996). Dessa forma, viabilizar outros vínculos afetivos que fomentem o convívio com a alteridade do outro.

Por fim, em "Moisés e o monoteísmo" ([1939 (1934-38)] 1996), texto redigido em um período de tensão e dificuldades, marcado pela perseguição aos judeus e pelo prenúncio da deflagração de mais uma guerra, Freud afirma que todos os povos que odiavam os judeus haviam se tornado "cristãos apenas em épocas históricas tardias, amiúdes impulsionados a isso por sanguinolenta correção. [...] Sobrou-lhes, sob o delgado verniz de cristianismo, aquilo que eram seus ancestrais, que adoravam um politeísmo bárbaro" ([1939 (1934-38)] 1996, p.105), e que o ódio dos cristãos contra os judeus encobria o ódio destes contra os que os dominaram e violentamente os converteram. 


\section{Conclusão}

Como vimos, Sigmund Freud já no início de sua teoria percebeu o quanto o ódio e amor estavam presentes na vida do sujeito, consequentemente, nas relações sociais, e como é difícil saber qual desses está agindo, visto que aparecem sempre entremeados, de maneira ambivalente. Inicialmente acreditava que as pulsões sexuais representavam Eros, e o ódio e a agressividade representavam as pulsões de auto conservação; mas em 1920, Freud apresenta as pulsões sexuais e as de auto conservação como representantes de Eros, e o ódio como o representante da pulsão de morte. O teórico descreve, ainda, como muitas vezes a pulsão de vida faz uso da pulsão de morte a fim de preservar a vida e de conseguir a realização do desejo; como a ambivalência amor e ódio pode unir, assim como pode ser usado a fim de dominar e até mesmo aniquilar o outro; e como a humanidade ainda tem muito a aprender para conseguir conviver com mais amor, tolerância e respeito ao outro. A viabilização do diálogo e da escuta é fundamental para que se consiga um melhor convício, pois é a partir desses que podemos conhecer e conviver com o outro tão próximo, respeitá-lo enquanto sujeito e viver com a singularidade de cada um. 


\section{REFERÊNCIAS:}

CHEMAMA, Roland. (Org.). Dicionário de Psicanálise. Porto Alegre: Artes Médicas, 1995.

FREUD, Sigmund. Além do princípio do prazer. In: Edição Standard Brasileira das Obras Completas de Sigmund Freud. Rio de Janeiro: Imago, [1920] 1996, v. XVIII.

- A interpretação dos sonhos. Edição Standard Brasileira das Obras Completas de Sigmund Freud. Rio de Janeiro: Imago, [1900] 1996, v. IV.

- A interpretação dos sonhos. Edição Standard Brasileira das Obras

Completas de Sigmund Freud. Rio de Janeiro: Imago, [1901] 1996, v. V.

Luto e melancolia. In: Edição Standard Brasileira das Obras Completas de Sigmund Freud. Rio de Janeiro: Imago, [1917a (1915)] 1996, v. XIV.

Moisés e o monoteísmo. In: Edição Standard Brasileira das Obras Completas de Sigmund Freud. Rio de Janeiro: Imago, [1939 (1934-38)] 1996, v. XXIII.

O ego e o id. In: Edição Standard Brasileira das Obras Completas de Sigmund Freud. Rio de Janeiro: Imago, [1923] 1996, v. XIX.

O mal-estar da civilização. In: Edição Standard Brasileira das Obras Completas de Sigmund Freud. Rio de Janeiro: Imago, [1930 (1929)] 1996, v. XXI.

. Os instintos e suas vicissitudes. In: Edição Standard Brasileira das Obras Completas de Sigmund Freud. Rio de Janeiro: Imago, [1915] 1996, v. XIV.

Por que a guerra? In: Edição Standard Brasileira das Obras Completas de Sigmund Freud. Rio de Janeiro: Imago, [1933 (1932)] 1996, v. XXII.

. Psicologia de grupo e a análise do ego. In: Edição Standard Brasileira das Obras Completas de Sigmund Freud. Rio de Janeiro: Imago, [1921] 1996, v. XVIII. Reflexões para os tempos de guerra e morte. In: Edição Standard Brasileira das Obras Completas de Sigmund Freud. Rio de Janeiro: Imago, [1917b] 1996, v. XIV. Sobre o narcisismo: uma introdução. In: Edição Standard Brasileira das Obras Completas de Sigmund Freud. Rio de Janeiro: Imago, [1914] 1996, v. XIV.

Três ensaios sobre a teoria da sexualidade. In: Edição Standard Brasileira das Obras Completas de Sigmund Freud. Rio de Janeiro: Imago, [1905] 1996, v. VII. Totem e Tabu. In: Edição Standard Brasileira das Obras Completas de Sigmund Freud. Rio de Janeiro: Imago, [1912-13] 1996, v. XIII. 


\title{
What Sigmund FreUd TelLS Us About Hate?
}

\begin{abstract}
The hate and love appear in the work of Sigmund Freud (1856-1939) often in a simultaneous and ambivalent way; when speaking of one, it is briefly commented on briefly on the other. Although the theorist has not defined hated as a concept, this affection appears in several moments of the elaboration of his theory, from the clinical texts to the social texts, demonstrating their importance in the process of formation of the subject, of the relations of identification that it establishes throughout the life and, consequently, of the affective bonds that circulate through the society. The reading of the Freudian texts helps us to understand better why it is so easy for man to make use of hate speech and even aggressive and violent actions in living with the other.
\end{abstract}

KEYWORDS: Hate; Psychoanalysis; Identification. 


\section{Que Nous Dit Sigmund Freud À \\ Propos De la haine?}

\section{RÉSUMÈ}

La haine et l'amour apparaissent dans les travaux de Sigmund Freud (1856-1939) souvent de manière simultanée et ambivalente; quand on parle de l'un, il est brièvement commenté brièvement sur l'autre. Bien que le théoricien n'ait pas défini la haine en tant que concept, cette affection apparaît à plusieurs moments de l'élaboration de sa théorie, des textes cliniques aux textes sociaux, démontrant ainsi leur importance dans le processus de formation du sujet, des relations d'identification qu'elle établit tout au long de la vie et, par conséquent, des liens affectifs qui circulent dans la société. La lecture des textes freudiens nous aide à mieux comprendre pourquoi il est si facile d'utiliser un discours de haine et même des actions agressives et violentes en vivant avec l'autre.

MotS-CLÉS: Haine; Psychanalyse; Identification. 
O Estatuto Da Interpretação Em Psicanálise

RECEBIDO EM 16-04-2019

APROVADO EM 25-10-2019

C 2019 Psicanálise \& Barroco em revista

http://www.seer.unirio.br/index.php/psicanalise-barroco/index

revista@psicanaliseebarroco.pro.br

Programa de Pós-Graduação em Memória Social — UNIRIO

Memória, Subjetividade e Criação

www.memoriasocial.pro.br/proposta-area.php 